\title{
CHANGES IN THE RUSSIAN REGULATORY BASE OF THE BUDGET PROCESS IN JUNE 2015
}

\author{
M.Goldin
}

In June the procedure for carrying out by the Ministry of Construction of the Russian Federation of in-house control over procurement for federal needs.

By Order No.330/pr of 30 April 2015 of the Ministry of Construction of the Russian Federation, the Procedure for Carrying Out by the Ministry of Construction of the Russian Federation of In-House Control over Purchases for Federal Needs was approved. The above procedure regulates the in-house control carried out by the Ministry of Construction of the Russian Federation over purchases of goods, jobs and services for federal needs (hereinafter the in-house control) and compliance with other legislative and statutory acts in the area of purchasing of goods, jobs and services for state and municipal needs.

The in-house control is aimed at checking compliance by the customer of the following requirements of the Russian legislation to planning and carrying out of state procurement:

- compliance with limitations and bans established by the legislation of the Russian Federation on the specific pattern in the area of procurement;

- compliance with requirements to justification of purchases, the initial (maximum) price of the contract (or the price of the contract concluded with a sole provider) and a method of identification of the provider (contractor and performer) and establishment of additional requirements (if any) to participants in procurement;

- compliance with requirements on quotas setting in procurement;

- compliance of the information on the volume of financial provision included in procurement plans with the information on the volume of financial provision for making procurements approved and brought to the notice of the customer;

- compliance with requirements applied to participation in procurements of small business entities and socially-oriented non-profit entities;

- compliance with requirements to identification of the provider (contractor and performer);

- compliance of the goods delivered, jobs done (its outputs) and services rendered with terms and conditions of the contract and a number of other requirements.

In-house control is carried out by means of field or documentary measures of in-house control.

Though it is not directly specified in the Procedure, deemed as field measures are sooner the following: inspection, reviewing, revised estimation, due diligence, inventory auditing and inspection measurement of volumes of jobs and other activities related to actual checking of compliance by the entity with control over legislative requirements in the field of procurement. Deemed as documentary measures is probably examination of documents and other materials provided at request on such activities of customers as are related to the subject of the control.

On the basis of the outputs of measures of in-house control, a certificate of audit is issued and approved by the head of the working group of inspection and signed by officials who are responsible for carrying out of in-house control measures.

In case of objections to or complaints about conclusions specified in the certificate of audit, the manager of the customer is in a position within a period of 3 days from the day of receipt of a copy of the certificate of audit to provide in writing objections which are attached to the materials of fulfilment of in-house control measures.

On the basis of the results of in-house control measures, the head of the working group of inspection submits to the minister, designated substitute or authorized person a written report with enclosure of the certificate of audit and objections (if any) from the unit which was subjected to in-house inspection.

In case of identification of violations on the basis of the results of fulfilment of in-house control measures, officials authorized to carry out in-house control measures develop and approve the plan of elimination of the identified violations. The plan of elimination of the identified violations is developed and signed by an authorized person of the Administrative and Personnel Department and submitted to the minister in the period within 14 (fourteen) days from the day of signature of the certificate of audit. 